\title{
Power-Aware Real-Time Scheduling based on Multi-Granularity Resource Reservation
}

\author{
Joohyung Sun $^{+} \cdot$ Hyeonjoong $\mathrm{Cho}^{++}$
}

\begin{abstract}
We proposes a power-aware fixed-priority real-time scheduling algorithm for multimedia service, called static voltage scaling algorithm with multi-granularity resource reservation (STATIC-MULTIRSV). The multi-granularity resource reservation was introduced to deliver higher system utilization and better temporal isolation than the traditional approaches in [2]. Based on this, our STATIC-MULTIRSV is designed to reduce the power consumptions while guaranteeing that all $\mathrm{I}$-frames of each video stream meet their deadlines. We implemented the proposed algorithm on top of ChronOS Real-time Linux [6]. We experimentally compared STATIC-MULTIRSV with other existing methods which showed that STATIC-MULTIRSV reduce power consumption by maximum $15 \%$ compared to its experimental counterparts.
\end{abstract}

Keywords : Real-time Scheduliing, Dynamic Voltage Scaling, Multimedia, Resource Reservation, Multi-granularity

\section{다중 세분화 자원 예약 기반의 저전력 실시간 스케쥴링 기법}

\author{
선 주 형 ${ }^{\dagger}$ 조 현 중 ${ }^{+\dagger}$
}

\begin{abstract}
요
약

본 논문에서는 멀티미디어 서비스를 위한 파워-효율적인 고정 우선순위의 실시간 스케쥴링 알고리즘으로 다중 세분화 자원 예약 기반의 정 적 전압 조절 알고리즘 (STATIC-MULTIRSV)을 제안한다. 다중 세분화 자원 예약은 전통적인 데드라인 기반의 자원 예약 보다 높은 연산 자 원 사용률과 더 나은 태스크간 독립성을 제공하는 모델로서 [2]에서 소개된바 있다. 다중 세분화 모델을 기반으로 제안된 STATIC-MULTIRSV 알고리즘은 비디오 스트림들의 I-프레임들을 각각의 데드라인을 모두 만족하는 것을 보장하면서 파워 소비를 줄이도록 고안되었다. 제안된 알고리즘은 실시간 리눅스[6] 상에서 구현을 통해 실험적으로 기존의 방법에 비해 파워 소모를 최대 $15 \%$ 까지 줄였음을 보 였다.
\end{abstract}

키워드 : 실시간 스케쥴링, 동적 전압 조절, 멀티미디어, 자원 예약, 다중 세분화

\section{1. 서 론}

최근 스마트폰 등을 통한 $\mathrm{DMB}, \mathrm{IPTV}$, 화상회의 등 다양 한 멀티미디어 서비스들의 증가로 인해 임베디드 시스템은 사용자가 만족할만한 서비스의 질(QoS, Quality of Service) 을 제공하기 위한 많은 양의 연산을 필요로 한다. 이러한 많은 연산은 필연적으로 높은 전력 소모를 야기하므로 제한 된 배터리 수명을 갖고 있는 휴대 및 이동이 가능한 기기들

\footnotetext{
※ 이 논문은 2012년도 정부(교육과학기술부)의 재원으로 한국연구재단의 지원을 받아 수행된 연구임(No.2011-0011534).

$\dagger$ 비 회 원 : 고려대학교 컴퓨터정보학과 박사과정

† 종신회원 : 고려대학교 컴퓨터정보학과 부교수

논문접수:2013년 3월 22일

수 정 일 : 1 차 2013 년 5 월 31 일

심사완료 : 2013년 5월 31일

* Corresponding Author:Hyeonjoong Cho(raycho@korea.ac.kr)
}

은 전력 소모를 고려한 설계가 필수적이다.

임베디드 시스템에서 운영되는 실시간 소프트웨어는 시스 템의 목적을 달성하기 위해 주어진 시간적인 요구 사항 (Deadline, 이하 데드라인)을 만족시킬 수 있도록 설계되어 야 한다. 대표적인 실시간 서비스인 멀티미디어 서비스는 데드라인의 만족 정도가 서비스의 $\mathrm{QOS}$ 로 표현될 수 있는 실시간 서비스로 사용자가 원하는 $\mathrm{QOS}$ 를 제공하기 위해서 는 $\mathrm{QOS}$ 를 정량적으로 표현하고 이를 달성하기 위해 시스템 을 설계하는 것이 필요하다.

전통적인 멀티미디어 서비스의 $\mathrm{QOS}$ 표현에는 확률적인 방법이 있는데, 이는 태스크의 데드라인 만족(DeadlineMeet, 이하 데드라인 만족)의 시간적 분포를 표현할 수 없 다는 단점이 있다. 즉, 100 번의 태스크 실행 중 80 번의 데드 라인 만족이 일어나는 경우와 10 번 중 8 번의 데드라인 만족 
이 일어나는 경우가 존재할 때, 서비스의 질 면에서는 두 경 우가 상이하지만, 확률적으로는 같은 $80 \%$ 로 이들을 구분 할 수 없다. 이러한 단점을 해결하기 위해 매 일정 시간 동안 데드라인 만족(그리고 불만족)의 분포에 제한을 두어 멀티미 디어 서비스의 $\mathrm{QOS}$ 및 데드라인 불만족에 대한 시스템의 내 성(Tolerance)을 확률적이 아닌 결정적으로(Deterministic) 정확하게 표현할 수 있는 약경성 (Weakly-hard) 실시간 제 약이 제안되었다[1].

한편 멀티미디어 서비스의 $\mathrm{QOS}$ 를 필요로 하는 실시간 시 스템의 특성을 나타내기 위한 또 다른 방법으로 자원 예약 기반의 다중 세분화 (Resource Reservation-based MultiGranularity, 이하 MG) 모델이 제안되었다[2]. 이 예약 기반 모델은 기존의 최악 상황을 고려한 예약 모델과는 다르게 MPEG 비디오 스트림 같은 많은 멀티미디어 어플리케이션 의 (1) 연산 자원 요구량이 급격히 변하고, (2) 최악상황의 연산 자원 요구량이 평균 연산 자원 요구량에 비해 너무 크 고, (3) 연산량이 많은 요청에 의한 태스크의 긴 버스트 시 간(Burst Time) 및 (4) 가끔씩 생기는 데드라인 불만족을 허용할 수 있는 특징들을 모두 고려했다. 본 연구에서도 멀티미디어 서비스를 처리하기 위해 이 $\mathrm{MG}$ 모델을 실시간 태스크에 적용시킨다.

한편 회로의 전력 소모를 줄이기 위해 많은 집적 회로 제 조사들은 클락 주파수와 연동되어 있는 공급 전압을 상황에 따라 동적으로 조절함으로써 전력소모를 줄일 수 있는 동적 전압 조절(Dynamic Voltage Scaling, DVS)기능을 포함한 저전력 프로세서들을 개발해왔다. 인텔의 XScale, $\mathrm{AMD}$ 의 모바일 애슬론, 삼성의 Cortex가 좋은 예다. CMOS 회로의 에너지 소비량은 공급 전압의 2차식()[3]을 따르기 때문에, 공급 전압을 낮추는 방법은 에너지 소비를 줄이는 효과적인 기술 중에 하나이다. Pillai[4]는 시스템 시작 전에 결정되는 정적 우선순위를 갖는 실시간 태스크의 온라인 DVS 스케쥴 링 기법을 제안했다. Pillai는 시스템 시작 전에 최악상황 반 응시간 (Worst-case Response Time, WCRT 또는 WR) 분 석을 기반으로 모든 태스크들의 데드라인을 만족하는데 필 요한 클락 속도 중 가장 낮은 수치를 찾아 놓고, 시스템 시 작 후 태스크가 일찍 끝남으로써 생기는 시스템의 남는 시 간 (Slack Time) 을 자신 보다 높은 우선순위를 갖는 태스 크에게 추가로 할당해 ccRM (cycle-conserving Rate Monotonic) 알고리즘을 제안한바 있다.

본 연구에서는 앞서 설명한 MG 모델에 맞는 WCRT 분 석 방법을 새롭게 설계하고, 이를 이용해 시스템 시작 전에 태스크들의 데드라인을 만족하는데 필요한 클락 속도 중 가 장 낮은 값을 찾는 방법을 제안한다. 또 (1) 최소한의 멀티 미디어 $\mathrm{QOS}$ 를 제공하면서도, (2) 시스템의 파워 소모를 줄 이기 위해 단일 프로세서 상의 멀티미디어 서비스를 위한 저전력 실시간 스케쥴링 알고리즘을 제안한다.

제안 알고리즘의 성능을 기존 방법과 비교 및 분석하기 위해 ChronOS Real-time Linux[6]가 설치된 DELL i7$2630 \mathrm{QM}$ 에서 이들을 구현하고, 구현 시스템에서 발생하는
실제 파워를 전기 계측/측정 장비인 WT210[5]으로 측정하 며 실험하였다.

\section{2. 본 론}

\section{1 시스템 모델}

1) 태스크 모델

$n$ 개의 주기적 태스크들의 집합은 $\left\{\tau_{1}, \tau_{2}, \ldots, \tau_{i}, \ldots, \tau_{n}\right\}$ 으 로 표기한다. 각각의 태스크들은 서로 독립적이며, 우선순위 순서로 나열되어 있다. 태스크들의 우선순위는 주기가 짧을 수록 높은 우선순위를 갖는 정적 우선순위 기반의 RM (Rate-Monotonic) 스케쥴링으로 결정 한다. 즉, 주기 $(T)$ 가 가장 짧은 $\tau_{1}$ 이 가장 높은 우선순위를 갖고, 주기가 가장 긴 $\tau_{n}$ 이 가장 낮은 우선순위를 갖는다. 각각의 태스크는 $\tau_{i}=$ $\left\{\right.$ prio $\left._{i}, T_{i}, C_{i}, D_{i}\right\}$ 으로 표기되며, $\operatorname{prio}_{i}$ 는 태스크의 우선순 위, $T_{i}$ 는 주기, $C_{i}$ 는 최악상황의 실행시간, $D_{i}$ 는 데드라인이 다. 여기에서 $T_{i}$ 와 $D_{i}$ 는 같다고 가정한다 $\left(T_{i}=D_{i}\right)$.

\section{2) $\mathrm{MG}$ 모델}

전통적으로 사용했던 예약 모델 $\{C, T, D\}$ 대신에 Saewong이 제안한 $\mathrm{MG}$ 모델을 사용한다[2]. $\mathrm{MG}$ 모델은 $\{C, T, D\},\left\{C^{x}, \varepsilon^{x} T\right\}, \ldots,\left\{C^{y}, \varepsilon^{y} T\right\}$ 로 표기하고, 여기서 $\varepsilon^{x}$ $<\ldots<\varepsilon^{y}$, 그리고 $\forall_{i}, \varepsilon^{i} \in Z+$ 로 $x, y$ 는 각 Reserve 단계를 나 타내며, $\varepsilon$ 은 각 Reserve 주기를 순서대로 구분해준다. 여기 서 $\{C, T, D\}$ 는 가장 높은 단계의 Reserve로 매 T시간 마 다 $\mathrm{C}$ 만큼 제공되며, $\mathrm{D}$ 는 데드라인이다. $\left\{C^{x}, \varepsilon^{x} T\right\}$ 는 한 단 계 낮은 Reserve로 시간 $\varepsilon^{x} T$ 마다 평균적으로 $C^{x}$ 만큼 제공 된다는 뜻이다. 각각의 세분화 시간 구간 $\left(\varepsilon^{x} T\right)$ 마다 그 단계 에 해당하는 자원 $\left(C^{x}\right)$ 이 계속 제공된다. 만약에 태스크가 예약된 양보다 더 많이 사용하려고 한다면 자원을 제한하고 태스크가 더 이상 실행되지 않도록 한다. 이는 태스크의 우 선순위를 다른 일반 태스크(비실시간 태스크)와 같거나 또 는 더 낮은 우선순위까지 강등시킴으로써 구현된다.

\section{2 고정 클락 속도 결정 알고리즘}

1) 스케쥴링 동작 및 클락 속도 결정 방법

제안한 알고리즘 STATIC-MULTIRSV는 MULTIRSV[2] 의 스케쥴링과 같이 RM (Rate-Monotonic) 스케쥴링을 채 용한다. STATIC-MULTIRSV는 MG 모델 기반의 실시간 태스크가 주어졌을 때 스케쥴 가능성(Schedulability)을 유지 하면서 파워 소모를 줄이기 위해 시스템의 시작 전에 주파 수를 정적으로 설정하는데, 이 주파수는 $\mathrm{RM}$ 스케쥴러가 주 어진 실시간 태스크들의 데드라인을 모두 만족시키는 가능 한 가장 낮은 주파수로 결정된다. 해당 주파수는 $\mathrm{MG}$ 모델 적용을 위해 확장된 Pillai[4]의 최악상황 반응시간 분석을 바탕으로 계산된다. 
$\mathrm{RM}$ 스케쥴링에서 태스크의 최악상황 반응시간은 태스크 의 최악상황 실행시간과 자신보다 더 높은 우선순위를 갖는 태스크들이 선점하는 시간의 총 합으로 구해진다. 시간 구 간 $\left(t_{0}, t_{0}+t\right)$ 에서 클락 속도 요소를 고려하는 최대 선점시 간은 다음 식으로 계산되며 $P_{i}^{\left(t_{0}, t_{0}+t\right)}$ 로 표기한다. 이는 [2]에 서의 최대 선점시간 계산을 따르면서 $\mathrm{DVS}$ 를 고려하여 시스 템에서 주어진 클락 속도 $S_{l} \in\left\{S_{1}, \ldots, S_{n f} \mid S_{1}<\ldots<S_{n_{f}}\right\}\left(n_{f}\right.$ 는 클락 속도 요소의 총 개수) 중 선택된 속도 $S_{l}$ 를 기반으 로 최악상황 실행시간 $\left(C_{i}\right)$ 을 $\frac{C_{i}}{S_{l}}$ 로 새로 계산한 식이다.

$$
\begin{aligned}
& P_{i}^{\left(t_{0} t_{0}+t\right)}=\operatorname{MIN}\left(\left\lfloor\frac{t}{\varepsilon_{i}^{g_{i}} T_{i}}\right\rfloor \frac{C_{i}^{g_{i}}}{S_{l}}+\left\lfloor\frac{t-m^{g_{i}}}{\varepsilon_{i}^{\left(g_{i}-1\right)} T_{i}}\right\rfloor \frac{C_{i}^{\left(g_{i}-1\right)}}{S_{l}}\right. \\
& +\ldots+\left\lfloor\frac{t-\left(\sum_{j=2}^{g_{i}} m^{j}\right)}{\varepsilon_{i}^{1} T_{i}}\right\rfloor \frac{C_{i}^{\mathrm{l}}}{S_{l}}+\left(t-\left(\sum_{j=1}^{g_{i}} m^{j}\right)\right),\left\lfloor\frac{t}{\varepsilon_{i}^{g_{i}} T_{i}}\right\rfloor \frac{C_{i}^{g_{i}}}{S_{l}} \\
& +\left\lfloor\frac{t-m^{g_{i}}}{\varepsilon_{i}^{\left(g_{i}-1\right)} T_{i}}\right\rfloor \frac{C_{i}^{\left(g_{i}-1\right)}}{S_{l}}+\ldots+\left\lceil\frac{t-\left(\sum_{j=2}^{g_{i}} m^{j}\right)}{\varepsilon_{i}^{1} T_{i}}\right\rceil \frac{C_{i}^{\mathrm{l}}}{S_{l}}, \ldots, \\
& \left\lfloor\frac{t}{\varepsilon_{i}^{g_{i}} T_{i}}\right\rfloor \frac{C_{i}^{\theta_{i}}}{S_{l}}+\left\lceil\frac{t-m^{g_{i}}}{\varepsilon_{i}^{\left(g_{i}-1\right)} T_{i}}\right\rceil \frac{C_{i}^{\left(g_{i}-1\right)}}{S_{l}}, \\
& \left.\left\lceil\frac{t}{\varepsilon_{i}^{g_{i}} T_{i}}\right\rceil \frac{C_{i}^{\theta_{i}}}{S_{l}}\right)
\end{aligned}
$$

여기에서 $m^{x}=\left\lfloor\frac{t-m^{(x+1)}}{\varepsilon_{i}^{x} T_{i}}\right\rfloor \varepsilon_{i}^{x} T_{i}, \quad m^{\left(g_{i}+1\right)}=0, \quad C_{i}^{1}=C_{i}, \quad \varepsilon_{i}^{1}$ $=1, g$ 는 세분화 단계 $\left(g_{2}\right.$ 는 2 단계).

다중 세분화 리소스 예약 시스템에서 $\tau_{i}$ 의 최악상황 반응 시간 $\mathrm{w}$ 은 다음 식을 따른다[2].

$$
w^{k+1}=\frac{C_{i}}{S_{l}}+\sum_{j<i} P_{j}^{\left(0, w^{k}\right)}
$$

여기서 $P_{j}^{\left(0, w^{k}\right)}$ 는 구간 $\left(0, w^{k}\right)$ 에서 $\tau_{i}$ 보다 높은 우선순위를 갖는 태스크들의 선점시간이다.

식 (2)는 시스템에서 주어진 클락 속도 중에서 다음의 조 건을 만족하는 가장 작은 클락 속도 요소 $S_{l}$ 을 찾기 위해 이용된다. $\mathrm{k}$ 는 0 부터, 즉, $w^{0}=\frac{C_{i}}{S_{l}}$ 부터 재귀적으로 시작하고, $w^{k+1}=w^{k}$ 일 때 “성공” 으로 끝나서 가장 최근에 선택된 $S_{l}$ 을 고정 클락 속도로 설정하거나, $w^{k+1}$ 가 $D_{i}$ 을 넘어가게 되면 $\left(w^{k+1}>D_{i}\right)$ “실패”로 끝나 고정 클락 속도를 $S_{n f}$ 로 설정한 다. 식 (2)를 통해 선택된 $S_{l}$ 에 대해서 “성공”일 경우, 각각 의 태스크에 대해서 최악상황 반응시간이 $w^{k+1}=w^{k} \leq D_{i}$ 이므 로 $\mathrm{RM}$ 스케쥴링 기반의 최악상황 반응시간 분석[4]에 의해 서 스케쥴 가능하다.

식 (2)의 시간 복잡도는 주어진 태스크들의 총 개수(n)와 가능한 클락 속도의 총 개수 $\left(n_{f}\right)$ 뿐만 아니라 세분화 단계 $\left(g_{i}\right)$ 에 의해서도 영향을 받는다. 여기서 $n_{f}$ 와 $g_{i}$ 는 상수로, 시스템 시작 전에 연산되는 식 (2)의 복잡도는 $O\left(n^{2}\right)$ 이다. 그리고 시스템 동작 시에는 복잡도가 $O(n)$ 인 $\mathrm{RM}$ 스케쥴링 기반으로 동적으로 동작한다.

\section{2) 예제}

다음 Table 1과 Fig. 1은 제안한 알고리즘이 MG 모델 기반의 일반적인 실시간 태스크 집합이 주어졌을 때 고정 클락 속도를 찾는 예제이다. Table 1은 $\mathrm{MG}$ 모델 기반의 태 스크 집합이다. 시스템 시작 전에 주어진 태스크 집합과 식 (2)로 고정 클락 속도를 계산한다. 먼저, 시스템이 제공하는 고정 클락 속도 $S_{l}$ 에 대응되는 주파수(frequency)가 freq $=\{0.75,0.8,0.85,0.9,0.95,1.0\}$ 으로 주어진다고 가정한다.

먼저 $\mathrm{freq}_{2}=0.8$ 일 때, 최악상황 반응시간을 계산해 스케쥴 가능성을 계산하면, $\tau_{1}$ 일 때 $w^{0}=1.25, w^{1}=1.25$. 즉, $w^{0}=w^{1}$ $=1.25<3$ 으로 “성공”, $\tau_{2}$ 일 때 $w^{0}=1.25, w^{1}=2.5, w^{2}=2.5$. 즉, $w^{1}=w^{2}=2.5<4$ 으로 “성공”, $\tau_{3}$ 일 때 $w^{0}=1.25, w^{1}=3.75, w^{2}=4.5$, $w^{3}=5.5, w^{4}=6.25$. 즉, $w^{4}=6.25<6$ 으로 “실패" 이기 때문에 다 음 freq $_{3}=0.85$ 로 앞에서 했던 방법으로 다시 계산한다. 그럼 주어진 $\mathrm{freq}_{3}$ 에서 모든 태스크 $\tau_{1}, \tau_{2}, \tau_{3}$ 의 최악상황 반응시 간이 모두 데드라인을 넘지 않기 때문에 freq $q_{3}$ 에 대응되는 고정 클락 속도가 정해진다.

Fig. 1은 고정 클락 속도가 정해졌을 때 실제로 일어나는 스케쥴링을 보여준다. Fig. $1 \mathrm{~A}$ 는 $f r e q_{n}=1$ 로 스케쥴링 되고, Fig. $1 \mathrm{~B}$ 는 freq $_{2}=0.8$ 로 스케쥴링 되는데 앞에서 스케쥴 가능 성 테스트에서 “실패"였기 때문에 $t=6$ 에서 $\tau_{3}$ 이 데드라인 불만족된다. Fig. $1 \mathrm{C}$ 는 스케쥴 가능성을 처음 “성공” 했던 $\mathrm{freq}_{3}=0.85$ 로 스케쥴링 되는 것을 보여준다. 앞서 수식에서 예측된대로 스케쥴 가능성을 “성공” 했기 때문에 모든 태스 크가 데드라인을 만족함을 시각적으로 알 수 있다.

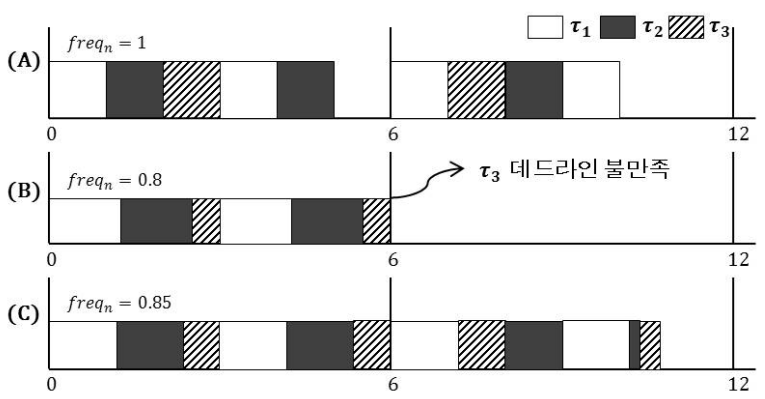

Fig. 1. Real-time Scheduling

Table 1. Real-time Task Sets

\begin{tabular}{|c|c|}
\hline Tasks & MG reservation model, Reserve \\
\hline$\tau_{1}$ & $\{\{1,3,3\},\{4,30\}\}$ \\
\hline$\tau_{2}$ & $\{\{1,4,4\},\{4,40\}\}$ \\
\hline$\tau_{3}$ & $\{\{1,6,6\},\{5,60\}\}$ \\
\hline
\end{tabular}




\section{3 실험 방법}

제안한 알고리즘 STATIC-MULTIRSV을 ChronOS Real-time Linux[6]가 설치된 DELL i7-2630QM 플랫폼 상에서 구현하고, 시스템의 파워 소모를 전기 계측/측정 장비인 WT210[5]으로 측정했다. ChronOS는 실시간 리눅 스 패치로, 리눅스에서 실시간 처리를 가능(CONFIG _PREEMP_RT)하게 해줌으로써 실시간 스케쥴링을 위한 리 눅스 커널 테스트베드를 제공해준다. STATIC-MULTIRSV 과의 성능 비교를 위해 기존 MULTIRSV를 실험 비교 대상 으로 삼았다.

\section{4 실험 플랫폼 및 환경}

실험 환경이나 검증 방법은 [2]의 실험과 동일하게 설정 했다. 실험 플랫폼의 리눅스 상에는 기본 프로세스들이 디 폴트로 동작하고, 동시에 비디오 프레임들과 실시간/비실시 간 태스크들이 동작한다. Table 2는 [2]의 실험에 사용한 프 레임들의 통계치로, 모든 비디오 스트림은 IBBPBBPBBPBB 의 $\mathrm{GOP}$ (Group of Picture) 패턴을 사용한다. 그 외의 태스 크는 5 개의 실시간 태스크, 5 개의 비실시간 태스크로 짧거 나(1 10ms), 중간쯤이거나 $\left(10^{\sim} 100 \mathrm{~ms}\right)$, 긴 $\left(100^{\sim} 1000 \mathrm{~ms}\right)$ 주기 로 균일 확률분포(Uniform Distribution) 함수에 의해 결정 된다. 그리고 각각의 시나리오에 따라 주어진 전체 Utilization과 주기에 맞게 임의로 최악상황 실행시간이 설정 되고, 시스템 시작 후의 실제 실행시간은 최악상황에 가까 운 시간으로 설정된다. 먼저 프레임 태스크의 MPEG4 비디 오 디코딩을 위한 간단한 다중 세분화 Reserve는

$$
R=\left\{\left\{d t_{\max }, T, T\right\},\left\{d t_{\text {avg }}^{*} \text { gop, } T^{*} \text { gop }\right\}\right\}
$$

로 주어지는데, 여기에서 gop는 GOP의 크기, T는 프레임의 주기, $d t_{\max }$ 는 최대 디코딩 시간, $d t_{a v g}$ 는 평균 디코딩 시간 이다.

Table 2. Video Frame Statistics

\begin{tabular}{|c|c|c|c|c|}
\hline 프레임 통계 & Jurassic & Lambs & News & Lecture \\
\hline 압축률 (YUV:MP4) & 9.92 & 13.22 & 10.52 & 36.27 \\
프레임 비율 & 25 & 25 & 25 & 25 \\
실행시간 (ms) & $3.6 \mathrm{e}+06$ & $3.6 \mathrm{e}^{+} 06$ & $9 \mathrm{e}^{+} 05$ & $3.6 \mathrm{e}+06$ \\
프레임 크기의 평균 & $3.8 \mathrm{e}+03$ & $2.9 \mathrm{e}^{+} 03$ & $3.6 \mathrm{e}+03$ & $1 \mathrm{e}^{+} 03$ \\
프레임 크기의 분산 & $5.1 \mathrm{e}+06$ & $5.2 \mathrm{e}+06$ & $6.3 \mathrm{e}+06$ & $8.3 \mathrm{e}^{+} 05$ \\
프레임 크기의 공분산 & 0.59 & 0.80 & 0.70 & 0.87 \\
프레임 크기의 최소 & 72 & 158 & 123 & 344 \\
프레임 크기의 최대 & 16745 & 22239 & 17055 & 7447 \\
평균 시스템 사용률 & 0.103 & 0.0905 & 0.1025 & 0.064 \\
\hline
\end{tabular}

프레임 이외의 실시간 태스크들의 다중 세분화 Reserve 는 다음 식으로 주어진다.

$$
R=\left\{\left\{C_{i}, T_{i}, T_{i}\right\},\left\{C_{i}, T_{i}\right\}\right\}
$$

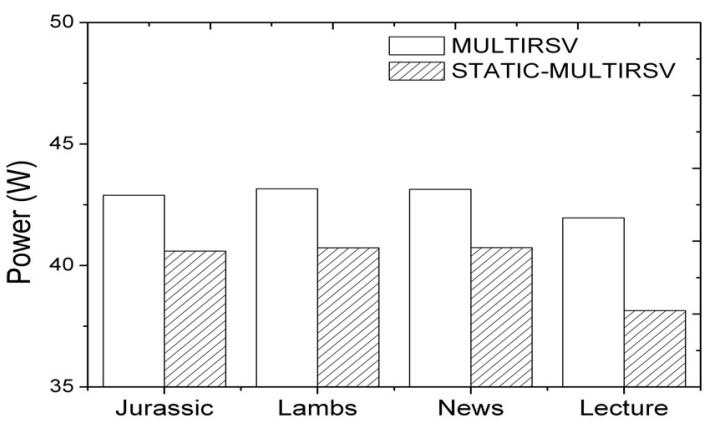

(A) $R T-U=0.4 / U=0.5$

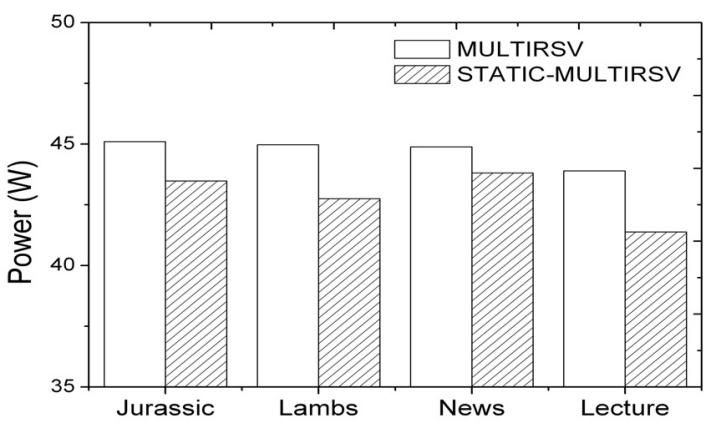

(B) RT-U $=0.65 / U=0.75$

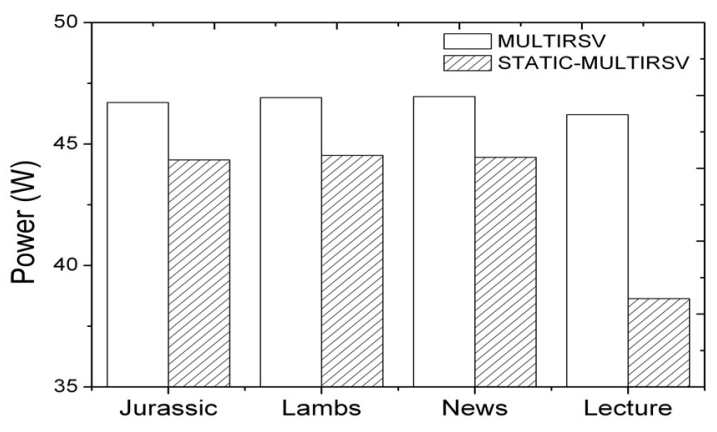

(C) $R T-U=0.4 / U=1.0$

Fig. 2. Power-efficient experimental results

스트림을 위한 $(\mathrm{m}, \mathrm{k})-\mathrm{firm}$ 데드라인 조건[7]은 $\left(m_{m p e g}, k_{m p e g}\right)=\left(\frac{d t_{a v g}^{*} g o p}{d t_{\max }}, g o p\right)$ 로 [2]와 같은 방법 으로 실험한다. 각 프레임의 비디오 디코딩 시간은 해당하 는 프레임 크기에 비례한다. 다음 측정치는 스케쥴링 알고 리즘 성능을 평가하는데 사용된다.

- Miss frames: 모든 프레임들의 데드라인 불만족 개수

- Miss I-frames: 모든 프레임들의 총 개수 대비 I-프레임 데드라인 불만족 개수 비율

- Miss BP-frames: 모든 프레임들의 총 개수 대비 B 및 $\mathrm{P}$-프레임 데드라인 불만족 개수 비율

- Dyn: dynamic error([7]에서 정의한 $\mathrm{k}$ 개의 연속된 프레임 에서 $\mathrm{m}$ 개 미만으로 시간 조건이 만족됐을 때 생기는 Dynamic Failure와 같은 의미) 대비 가능한 $\mathrm{k}$ 개의 연속 된 프레임 집합들의 총 개수 


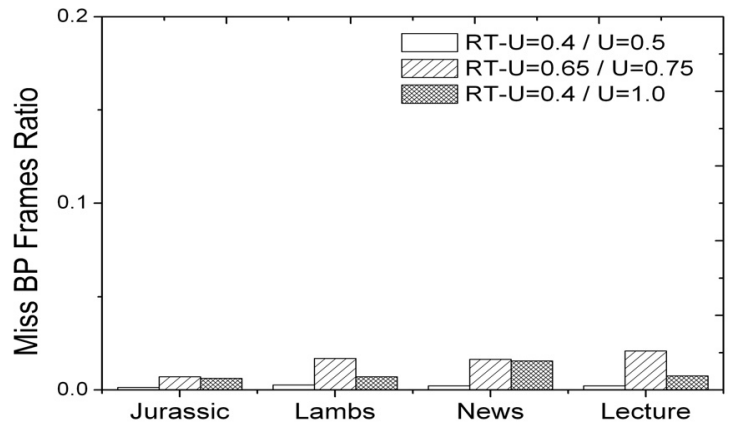

(A) MULTIRSV

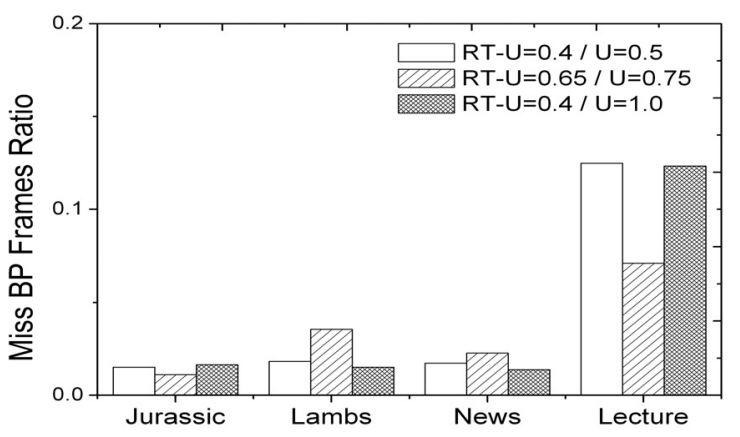

(B) STATIC-MULTIRSV

Fig. 3. Experimental results for performance (No Missed I-frames and No Dynamic Error)

실험은 앞에서 언급한 총 10 개의 실시간 및 비실시간 태 스크들과 Jurassic, Lambs, News, Lecture의 각 프레임에 대하여 총 세 개의 실험 시나리오로 진행한다. 먼저 각 시 나리오에 대해서 실시간 태스크들의 시스템 사용률 (Real-time Utilization, 이하 RT-U), 비실시간 태스크들의 시스템 사용률 (Non- real-time Utilization, 이하 NRT-U), 전체 시스템 사용률(System Utilization, 이하 U)을 서로 다 르게 정하는데, 이 사용률에는 비디오 프레임 사용률이 포 함되어 있지 않다. 즉, 비디오 프레임 사용률을 제외한 시스 템의(실시간 태스크들의) 작업량을 의미한다.

세 가지 시나리오는 각각 (1) 적은 작업량: $\mathrm{RT}-\mathrm{U}=0.4 / \mathrm{U}=0.5$, (2) 높은 작업량: $\mathrm{RT}-\mathrm{U}=0.65 / \mathrm{U}=0.75$, (3) 적은 작업량, 높은 백그라운드 작업량 $(\mathrm{NRT}-\mathrm{U}=0.6)$ : $\mathrm{RT}-\mathrm{U}=0.4 / \mathrm{U}=1.0$ 으로 앞서 설명한 알고리즘 성능에 대한 요 소와 파워 소모에 중점을 맞춰 실험을 진행한다.

\section{5 실험 결과}

Fig. 2와 Fig. 3은 알고리즘, 시나리오, 비디오 프레임에 대한 실험 결과를 보여준다. 모든 실험에 대해서 Miss I-frames와 Dyn이 일어나지 않는다. 이는 본 논문에서 제안 한 기법이 최소한의 멀티미디어 $\mathrm{QOS}$ 를 보장함을 의미한다. 또 Fig. $2 \mathrm{~A}$ 와 Fig. $2 \mathrm{C}$ 에서 RT-U가 적을 때, 기존의 알고리 즘 보다 최대 $15 \%$ 의 파워 효율을 증가시켰음을 보여준다. 파워 효율이 증가된 이유는 RT-U가 적을수록 식 (2) 중 높은 우선순위를 갖는 태스크들의 선점시간 $(P)$ 이 적으므로
더 낮은 고정 클락 속도를 사용할 수 있기 때문이다.

반면, Fig. $2 \mathrm{~B}$ 와 같이 RT-U가 RM의 스케쥴 가능성의 한계 0.69 에 가까워질 경우 실시간성 보장을 위해 정적 알 고리즘의 클락 속도를 낮추는 것이 어려우므로 파워 효율이 좋지 않다. 대신 낮은 클락 속도에서는 태스크의 실행 시간 이 길어져 예약된 Reserve 양보다 더 많은 시간을 사용하게 되므로, Fig. 3에서 STATIC-MULTIRSV가 기존의 알고리 즘보다 더 많은 $\mathrm{B}, \mathrm{P}$-프레임의 데드라인을 놓치고 있는 것 을 볼 수 있다. 특히, Lecture 비디오 실험에서 상대적으로 많은 Miss BP-frames이 생기는 이유는 최대 프레임 크기가 작아서 식 (2)의 선점시간이 적어지고, 다른 프레임에 대한 실험에 비해 더 낮은 고정 클락 속도를 사용하게 되기 때문 이다.

그럼에도 불구하고 Miss I-frames와 Dyn이 모든 실험에 대해 일어나지 않으므로 STATIC-MULTIRSV는 최소한의 멀티미디어 $\mathrm{QoS}$ 를 제공하고 있음을 보여준다. I-프레임은 모든 비트 정보들을 갖고 있어서 디코딩 시 다른 프레임을 필요로 하지 않는 독립형 프레임이다. 만약에 $\mathrm{GOP}$ 는 12 , $\mathrm{fps}$ 는 25 인 멀티미디어 스트림이 존재할 때, 1 초에 23 개의 I-프레임만이라도 디코딩 한다면 영상이 0.5초 이상 멈춰있 는 현상을 없앨 수 있다. 반면 $\mathrm{P} / \mathrm{B}$-프레임들은 I-프레임을 참조하여 디코딩되는 프레임이다. 즉 $\mathrm{P} / \mathrm{B}$-프레임 디코딩 태 스크가 데드라인을 만족한다하더라도 I-프레임의 정보 없이 는 디코딩될 수 없으므로 $\mathrm{I}-$ 프레임 디코딩 태스크가 데드라 인을 만족하는 것은 중요하다. 그러므로 STATIC -MULTIRSV는 최소한의 멀티미디어 QOS를 해치지 않도록 $\mathrm{I}-$ 프레임 태스크의 데드라인을 항상 만족시킬 수 있는 최적 클락 속도를 찾아 동작한다.

\section{3. 결 론}

본 논문에서는 단일 프로세서 상의 멀티미디어 서비스를 처리하기 위해 실시간성을 포함한 최소한의 멀티미디어 $\mathrm{QOS}$ 를 제공하면서 시스템의 파워 소모를 줄이는 임베디드 실시간 스케쥴링 기법 STATIC-MULTIRSV를 제안했다. STATIC-MULTIRSV는 멀티미디어 의 QoS를 보장하기 위 해 MG 모델을 채택하고, 파워 소모를 줄이기 위해 DVS 기 술을 사용했다. 실제 구현을 통해 실험적으로 제안 스케쥴 링 알고리즘이 멀티미디어의 최소 성능을 보장하면서, 파워 효율을 최대 $15 \%$ 까지 증가시킴을 보였다.

\section{참 고 문 헌}

[1] Bernat, G., Burns, A., Liamosi, A. "Weakly hard real-time systems," Computers, IEEE Trans. on, Vol.50, No.4, pp.308-321, Apr., 2001.

[2] Saowanee Saewong, Ragunathan (Raj) Rajkumar. "Multi-Granularity Resource Reservations". IEEE RTSS, 2005. 
[3] BURD, T. D., BRODERSEN, R. W. "Energy efficient CMOS microprocessor design”. Hawaii International Conference on System Sciences, 1995.

[4] Padmanabhan Pillai, Kang G. Shin. "Real-time dynamic voltage scaling for low-power embedded operating systems". SIGOPS Oper. Syst. Rev. 35, 5 (October 2001), pp.89-102.

[5] YOKOGAWA. "White Paper of WT210/WT230 DIGITAL POWER METERS”. http://tmi.yokogawa.com/technical library/ white-papers/wt210wt230-digital-power-meters/

[6] Systems Software Research Group at Virginia Tech. "ChronOS Real-time Linux". http://chronoslinux.org/wiki /Main_Page

[7] Hamdaoui, M., Ramanathan, P. "A dynamic priority assignment technique for streams with ( $\mathrm{m}, \mathrm{k}$ )-firm deadlines," Computers, IEEE Trans. on, Vol.44, No.12, pp.1443-1451, Dec., 1995.

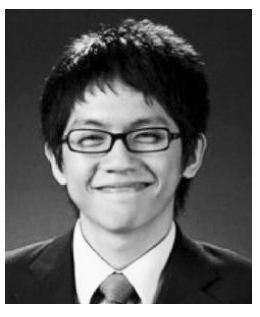

선 주 형

e-mail : joohyung_sun@korea.ac.kr 2010년 고려대학교 컴퓨터정보학과(학사) 2012년 고려대학교 컴퓨터정보학과(석사)

2012년 현 재 고려대학교 컴퓨터정보학과 박사과정

관심분야: Real-time scheduling, Energyaware algorithm, Resource reservation

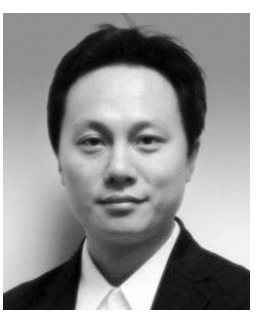

\section{조 현 중}

e-mail : raycho@korea.ac.kr

1996년 경북대학교 전자공학부(학사)

1998년 포항공과대학교 전자전기공학과 (석사)

2006년 9월 Computer Engineering,

Virginia Polytechnic Institute and State University, Blacksburg VA(Ph.D)

2009년 현 재 고려대학교 컴퓨터정보학과 부교수

관심분야: Real-time computing for embedded systems,

Human-computer interactions for smart devices 